Nunt. Antiquus, Belo Horizonte, v. 14, n. 1, p. 31-55, 2018

\title{
A recepção (praticamente) perdida: a Tebaida de José Agostinho de Macedo - apresentação e edição ${ }^{1}$
}

\section{The Reception (Nearly) Lost: Thebais by José Agostinho de Macedo-Presentation and Edition}

\author{
Leandro Dorval Cardoso \\ Universidade Estadual Paulista “Júlio de Mesquita Filho", Araraquara, São Paulo / Brasil \\ leandrodorvalc@gmail.com
}

Resumo: Tomando como fonte o manuscrito CXXII 2-2 da Biblioteca de Évora, este artigo traz à luz, em edição diplomática, o único fragmento conhecido da tradução integral do poema épico Thebais, de Públio Papínio Estácio (Publius Papinius Statius - séc. I d.C.), realizada por José Agostinho de Macedo e perdida antes que pudesse ter sido publicada. Para isso, em um primeiro momento, este artigo empreende um breve percurso pela biografia de Macedo, em especial por sua postura crítica e suas ideias sobre a tradução, com o objetivo de delinear um horizonte no qual e a partir do qual seu trabalho com o poema de Estácio possa ser compreendido. Dessa forma, será possível ressaltar a imagem do autor como uma figura importante na recepção dos clássicos greco-latinos em língua portuguesa.

Palavras-chave: José Agostinho de Macedo; tradução; Tebaida; Públio Papínio Estácio.

Abstract: Taking the manuscript CXXII 2-2 of the Évora Library as a source, this paper brings to light, in a diplomatic edition, the only known fragment of the complete translation of the epic poem Thebais by Publius Papinius Statius (1st century AD), performed by José Agostinho de Macedo and lost before it could have been published. In order to achieve this main objective, this paper undertakes a brief tour of the biography of Macedo at first, especially on his critical stance and his ideas on the translation, with the aim of delineating a horizon in which and from which his work with the poem

\footnotetext{
${ }^{1}$ Este artigo apresenta os resultados expostos em comunicação oral realizada durante o XX Congresso da Sociedade Brasileira de Estudos Clássicos (SBEC), realizado em 2015 na Universidade Federal de Ouro Preto (Mariana, MG), intitulada "José Agostinho de Macedo, tradutor da Tebaida".
} 
of Statius can be understood. In this way, it will be possible to emphasize the image of the author as an important figure in the reception of the Greco-Roman classics in Portuguese language.

Keywords: José Agostinho de Macedo; translation; Thebaid; Publius Papinius Statius.

Diferentes autores foram responsáveis por uma ampla retomada, via tradução, da literatura clássica greco-latina durante o Neoclassicismo lusitano, dentre os quais se podem destacar Filinto Elísio, Manuel Maria Barbosa du Bocage, José Maria da Costa e Silva, Elpino Duriense e José Agostinho de Macedo. Nesse contexto, portanto, a tradução se transforma em um veículo fundamental de retomada dos valores e modelos clássicos, tão importantes para as letras da época. José Agostinho de Macedo (1761-1831) é, sem dúvida, uma figura importante desse período, seja por suas opiniões contundentes a respeito de seus contemporâneos e de nomes já consagrados da literatura greco-latina e portuguesa, seja por suas práticas poéticas e de tradução, seja por suas posturas contrárias ao Liberalismo, ao Sebastianismo e à Maçonaria. Normalmente lembrado por causa da tradução das odes e dos epodos de Horácio (1806), Macedo também se empenhou em traduzir o poema épico Thebais, de Públio Papínio Estácio (Publius Papinius Statius - séc. I d.C.), autor pelo qual nutria grande estima, a ponto de colocá-lo à frente de Virgílio (infra). É, pois, ao intuito de resgatar a memória de Macedo e de sua tradução da Tebaida, que este artigo se dedica.

Para isso, antes de apresentar a edição dos 79 primeiros versos de sua Tebaida presentes no códice CXXII 2-2 da Biblioteca de Évora, proceder-se-á a uma retomada de algumas questões importantes sobre o autor. Levando em conta dados de sua biografia e a concepção de tradução a partir da qual realizava seus trabalhos, passando brevemente por algumas das posturas críticas mais polêmicas que adotou, será possível delinear um retrato não apenas de Macedo e de suas idiossincrasias responsáveis, em grande medida, pela (má) fama de seu estro poético e tradutório -, mas também do lugar que Estácio e a Tebaida ocuparam em sua caracterização como leitor dos clássicos, reforçando-se assim 
os contornos de seu papel durante um período fundamental na história da recepção da literatura greco-latina em língua portuguesa. Após esse percurso, será apresentada a edição diplomática dos fólios em que se encontra, no manuscrito em questão, o único fragmento conhecido da tradução que, a julgar por suas opiniões a respeito de Estácio (infra), deve ter-se mostrado como o mais importante dos empenhos tradutórios do autor.

José Agostinho de Macedo nasceu em Beja, no Alentejo, em 11 de setembro de 1761. Ingressou na Ordem de Santo Agostinho em 1778 como frade, mas foi expulso em 1792 após 14 anos de incontáveis crimes contra o estatuto da Ordem, passando a viver, então, do trabalho de sua própria pena. Em 1794, após ter interposto um Breve de Secularização junto à Cúria Romana, foi absolvido de todas as condenações anteriores e conduzido ao posto de presbítero secular. Em 1790, na companhia de Manuel Maria Barbosa du Bocage, o Elmano Sadino, e com o pseudônimo de Elmiro Tagídeo, ingressou na Nova Arcádia, título sob o qual renasceu a extinta academia literária conhecida como Arcádia Lusitana - e que viria a encerrar suas atividades definitivamente já no ano de 1794. Faleceu aos 70 anos em outubro de 1831, abatido por várias e sucessivas doenças, após publicar diversas obras literárias e um sem número de opúsculos críticos, gozando de grande fama como homem das letras, ainda que de opiniões bastante polêmicas. Entre elas, destacam-se as que se referem a grandes nomes da poesia como Camões e Homero, cuja Ilíada era, em suas palavras, "huma infernal salgalhada, huma barafunda confusissima, huma mixordia intolleravel" (MACEDO, 1841b, p. 40-41). ${ }^{2}$

Sobre Camões, seu parecer não foi menos contundente ou polêmico: para ele, o autor de Os Lusíadas não passava de um “copiador” de Virgílio, ao qual faltavam qualidades poéticas na criação da história escolhida, na disposição das partes da narrativa e na enunciação das imagens:

\footnotetext{
${ }^{2}$ Optou-se por manter, nas citações, a mesma ortografia encontrada nas fontes, de modo a criar uma harmonia entre as citações feitas durante o texto e a edição diplomática da tradução de Macedo, que encerra o presente artigo.
} 
Ora [...] comecei a contemplar as Lusíadas, e vi que a Fabula não era original, mas emprestada, e que ao Poeta faltava o genio da invenção, e que apenas se podia classificar entre os serviz imitadores: via que a disposição, e symmetria do edificio era por extenso defeituosa, pela desproporção de suas partes constituintes, ou integrantes; vi finalmente, que a elocução era sobre maneira desigual, e que naquelles tractos do Poema, em que não tomava, e copiava dos outros, cahia desleixadamente em termos baixos prosaicos, e dissonantes. (MACEDO, 1814, p. 52-53).

Essa postura diante do maior ícone da literatura nacional não tardou em receber respostas, e a voz de Antônio Maria do Couto foi a que, talvez, mais se tenha feito ouvir. No ano seguinte à publicação de Oriente (1814), em cujo "Discurso preliminar" Macedo delineia sua leitura do épico camoniano, ${ }^{3}$ dois textos de Couto vieram a público com a intenção de apontar seus defeitos. No primeiro deles, nomeado Breve análise do novo poêma que se intitula Oriente (1815a), Couto aponta as semelhanças entre os versos de Oriente e os de Gama, outro poema publicado por Macedo em 1811, acusando-o de cometer "[...] huma paródia servil”" (1815a, p. 7) de sua própria obra e concluindo que o “[...] novo Oriente he o Gama, e que se o Gama por seus nativos defeitos nada he, nada he tambem o Oriente" (1815a, p. 8.). O segundo, prolixamente nomeado Manifesto crítico, analítico e apologético: em que se defende o insigne vate Luiz de Camões, da mordacidade do discurso preliminar, que precede ao poema Oriente, e se demonstrão os infinitos erros do mesmo poema (1815b), em que Couto mantém seu intuito detrator de Oriente, foi precedido por uma tréplica de Macedo intitulada $A$ analyse analysada: resposta a Couto, por José Agostinho de Macedo (1815). Longe de se encerrar nisso, ${ }^{4}$ porém, a polêmica entre ambos se estendeu

\footnotetext{
${ }^{3}$ As quais, mais tarde, o autor desdobrou nos dois volumes de Censura das Lusíadas (1820).

${ }^{4}$ Nem teve início, pois, nesse momento, mas de antes já discordavam os autores. Em 1811, por exemplo, Couto já se manifestara a respeito dos Motins de Macedo, dizendo sobre os "solilóquios" que o compõem: "Cada Solliloquio roda sobre os mesmos eixos
} 
para além da morte de Macedo, quando Couto não mediu esforços para maldizê-lo em uma introdução biográfica à terceira edição dos Motins literários de Agostinho:

Pelo que temos dito se collige, que Macedo foi hum maníaco literário, que foi hum orgulhozo com talentos, e que se os tivera applicado bem sería respeitado, e serviria de ornamento á Patria, de brilho á republica das Letras, e de prazer á Sociedade; porém circulado de papeletas em que inutilizou o tempo; occupado noite, e dia em escriptos ephémeros de nenhuma entidade por infamantes, e injuriozos attrahio a geral execração, exarcebou os eruditos, que podião immortaliza-lo, e merecido a justa indignação de todo hum Publico, pelo que o espera a sorte dos Cherilos, Scióppios, e outros AA [autores] presumptuozos, e desvanecidos, sepultando-se com o sêo corpo sua memoria. (COUTO, 1841, p. 82-83).

Da mesma forma, as traduções de Macedo não receberam juízos muito distintos desses. Como se verá (infra), Bocage foi um grande crítico do trabalho de Elmiro, seja com relação aos poemas de próprio punho, seja às traduções. Sobre os versos com que traduziu Horácio, diz Bocage, na sátira intitulada Pena de Talião e dirigida a Macedo, que, "[...] aos sons piedosos" (v. 83) das elegias de Nasão, "que o Ponto ouviu com dor, com mágoa o Tibre,/ versos prepões, sarmático-latinos,/ versos, que inda ao burel, e ao claustro cheiram" (v. 84-86). Ainda sobre tradução de Horácio, além do menoscabo de seus contemporâneos, as críticas posteriores não deram ao trabalho um parecer melhor. Marcelino Menéndez y Pelayo (1885), por exemplo, sintetiza as posturas críticas e estéticas de Macedo, dizendo-o um escritor "[...] fecundíssimo e arbitrário, homem de variada erudição e de lúcido engenho, embora de

em diversos terrenos, quero dizer, a tal conversinha inflammatoria ad ephesios rexeada de reticencias toxicas, empalhada com allusões perturbadoras, e destillando por todos os poros, ou erros aquella baba caustica, que insinuada gangrena, e dissolve os corpos organisados a que se apega" (COUTO, 1811, p. 26). 
gosto escasso e abundante arrogância" (1885, p. 264). Para o autor, o volume das odes e epodos demonstram certa imaturidade com relação ao texto, dando a impressão de que as traduções foram feitas sem muito estudo e preparação prévios:

[Sua tradução] teve sempre fama escassa, talvez por ser tão condenada em Portugal a memória do cruel detrator de Camões; mas, julgando-o com imparcialidade, deve-se confessar que a tradução é um conjunto digno de apreço, embora não muito poética nem agradável. Padece de frequentes prosaísmos e abunda em versos fracos e ruins; mas poucas vezes erra o sentido, tendo precisão e exatidão quase sempre, apesar das liberdades que o tradutor gosta de tomar. O que falta é espírito horaciano e sensibilidade com relação às delicadezas e harmonias do original. Tem, além disso, traços de obra improvisada, sem preparação nem estudo suficientes, e por esse motivo não pode ser considerada como definitiva nem tomada por modelo. (MENÉNDEZ Y PELAYO, 1885 , p. 265).

Em se tratando da tradução da Tebaida de Estácio, no entanto, muito pouco nos restou, seja de sua recepção crítica, seja do próprio texto. De acordo com Innocêncio da Silva (SILVA, 1899, p. 36), um dos biógrafos de Macedo, a empresa teria sido iniciada em 1797, encerrando-se em pouco tempo e resultando em dois volumes nos quais se dividiram igualmente os doze cantos do poema. Esse trabalho, porém, diferentemente da tradução que fizera de Horácio, nunca veio a lume. Em carta remetida ao Fr. Domingos de Carvalho e datada de 1829, diz Macedo sobre o triste fim de um dos volumes de seu Estácio:

Sobre este valentissimo poeta vae uma digressão. Sempre me tocou muito seu fogoso enthusiasmo, e logo depois da minha transformação aos trinta annos eu traduzi todos os doze livros da Thebaida em optimos versos, que por bons que fossem nunca poderiam corresponder ao impeto e ao fogo do 
original, mas enfim eu a conclui, e deitava a obra a dois volumes em $4^{\circ}$. Que fatalidade! Empresto a um amigo o primeiro volume que continha os primeiros seis livros, depois mandando-o buscar, o moço o perdeu na rua juntamente com uns calções que me trazia de casa do alfaiate! Restam os seis últimos, que ahi estão, e eu sem animo para nova traducção dos primeiros. (MACEDO, 1900, p. 166).

Tal fato, também segundo Innocêncio da Silva, teria ocorrido em 1810, um pouco antes de Agostinho ter sido tomado, em 1813, por uma vontade de retraduzir os seis primeiros cantos perdidos. Essa empresa, porém, certamente não chegou a terminar, uma vez que em outras cartas já do final da vida ainda lamenta a perda do autógrafo de sua Tebaida sem nunca se referir a uma nova tradução na íntegra dos cantos perdidos de seu Estácio. Em missiva remetida ao Frei Joaquim da Cruz e provavelmente escrita em 1830, revela, contudo, ter retraduzido parte do primeiro canto do épico, que andaria, então, nas mãos de Antônio Feliciano de Castilho:

Tenho pena do Stacio, que nunca pude lêr, nem traduzir sem um violento arrepiamento de cabello, e tremor do cerebro; emfim, os seis ultimos livros existem, e parte do primeiro, porque eu a quiz começar, e existe na mão de um cego, filho do Castilho, que está em Coimbra, e posso mandar vir; mas o tempo presente não é para Stacio. (MACEDO, 1900, p. 69).

Em outra carta ao Frei Joaquim da Cruz e anterior a essa, mas datada do mesmo ano, Macedo, moribundo, diz ter-se decidido a retraduzir as Sátiras, as Epístolas e a Arte poética de Horácio, que ele já traduzira, mas também esse volume se perdera, dessa vez quando estava com Frei José Mariano Velloso em uma viagem ao Rio de Janeiro. Sempre alegando a superioridade de Estácio, declara:

Das obras de Horacio foge-me um capucho com o segundo volume, resta o primeiro impresso; das obras do maior poeta latino, Stacio, tambem traduzido, 
perde-me uma criada o primeiro volume, seis livros, e resta o segundo, que são outros seis livros, na mão de Lopes: que hei de fazer? O primeiro de um, ou o segundo do outro? Farei o segundo do outro, que é mais conhecido Horacio e mais estimado do mundo todo, porque o mundo todo tambem se engana no juizo dos poetas e de versos. (MACEDO, 1900, p. 66).

Sendo assim, os autógrafos do primeiro canto retraduzido e dos seis últimos cantos da Tebaida de Agostinho tiveram, ao que parece, destinos diferentes: em 1830, aquele estava com Antônio Feliciano de Castilho, enquanto este encontrava-se nas mãos de Joaquim José Pedro Lopes, seu amigo íntimo. Em suas Memórias para a vida íntima de José Agostinho de Macedo (SILVA, 1899, p. 263), Innocêncio da Silva reporta ambos os autógrafos como "Obras manuscritas que se reputam perdidas", e Theophilo Braga, organizador do livro de Innocêncio, como "Obras manuscritas de que há notícia e existem ao presente", dando as seguintes informações sobre os manuscritos da Tebaida:

- a existência de um manuscrito com os primeiros 79 versos da tradução na Biblioteca de Évora (Cod. CXXII - 2-2);

- a existência de duas entradas no catálogo da Livraria Pereira Merello: sob o número 361, “Thebaida, de Pe. José Agostinho de Macedo"; sob o número 691b, a descrição do manuscrito "Stacio - só o $2^{\circ}$ tomo";

- a conservação do manuscrito da retradução do primeiro canto na Coleção Ferreira da Costa.

Uma breve investigação sobre o destino tanto da Coleção Ferreira da Costa, como da Livraria Pereira Merello, revelou o seguinte: esta diz respeito à biblioteca particular do bibliófilo Agostinho Vito Pereira Merello, cujo catálogo encontra-se na Biblioteca Nacional de Portugal (BNP); aquela, à coleção particular de Francisco de Paula Ferreira da Costa, amigo íntimo de José Agostinho. Há, também na BNP, um catálogo das obras de sua coleção. Porém, ao menos do que se pode levantar, ambas 
as coleções foram desmanchadas e vendidas aos poucos, ${ }^{5}$ não constando a manutenção de seu acervo por nenhuma biblioteca ou instituição específicas. Para este artigo, então, foi tomado como fonte o Códice mantido pela Biblioteca de Évora e em cujos fólios encontram-se: uma carta assinada por José Agostinho e datada de 1800; uma composição poética intitulada Ode e dirigida ao Bispo de Beja; ${ }^{6}$ outra ode intitulada A existência d'Ode; um poema intitulado A Natureza - poema filosófico; e os 79 versos iniciais de sua Tebaida.

Os motivos que levaram Macedo à tradução do épico maior de Estácio podem ser encontrados em suas próprias manifestações críticas, por meio das quais exprimiu várias vezes a sua profunda admiração pelo poeta e o grande deleite que sua leitura lhe causava. Em um de seus solilóquios (n. 36), por exemplo, no qual discorre sobre a relação entre a obra de arte e o crítico - que deveria guiar o seu juízo a partir do interesse que a obra lhe causa -, declara a respeito de Estácio, e especificamente da Tebaida:

Nenhum me prende o coração com mais vivo interesse, nenhum me transporta com mais rapidez, força e viveza de hum affecto para outro, nenhum me faz alhear mais de mim mesmo, nenhum se senhorêa de minha alma com mais imperio do que Stacio. Este he o unico poeta que ha, com perdão de todos os seculos, de todos os rethoricões e de todos os pedantes do mundo; tem às vezes mais poezia em huma só página, que quantos alfarrabios de versos tem parido, e talvez parirão as cabeças humanas, filhas de Eva. O setimo, e undecimo livro da Thebaida, valem mil Eneidas, duas mil Jerusalem, três mil Paraizo Perdido. Malherbe, Francez, assim o julgou, o meu coração assim o diz e assim o sente. (MACEDO, 1841a, p. 295-296).

\footnotetext{
${ }^{5}$ De acordo com um artigo publicado por Altamirando Requião (1913) na Gazeta de Notícias da Bahia, após cair enfermo, Agostinho Merello teria autorizado a venda de sua biblioteca por questões financeiras.

${ }^{6}$ Trata-se de Manuel do Cenáculo, nomeado Bispo de Beja em 1770 e Arcebispo de Évora em 1802.
} 
O julgamento hiperbólico a respeito do poeta latino se repete por toda a sua obra. "Unico poeta que ha", Estácio ocupava posição central nas concepções de poesia de nosso autor, a ponto de Innocêncio da Silva atribuir tal opinião à semelhança estilística entre os escritos de Macedo e a Tebaida, um original que "se prestava maravilhosamente ao estylo turgido e emphatico, que o traductor adoptava para si em suas obras metrificadas" (1899, p. 36).

Mesmo que não existam juízos críticos claros sobre a Tebaida de Macedo, sabe-se que a obra foi uma das responsáveis pelas discussões entre ele e Bocage, as quais teriam começado ainda no tempo da Nova Arcádia e culminado na publicação, por parte Macedo, em 1801, de uma sátira atacando diretamente seu antigo conviva por causa do prefácio à tradução de As plantas, poema de Ricardo Castel, em que Bocage proclamava o seu próprio lugar no Parnaso, vangloriando-se por qualidades que ele mesmo atribuíra a si. No poema, a Sátira a Manuel Maria Barbosa du Bocage, ${ }^{7}$ Macedo ataca-lhe as empreitadas poéticas e tradutórias ora dizendo-lhe "tu és vadio, és magro, és pobre, és feio" (v. 22), ora "um despota em poesia" (v. 25), um "fanfarrão glosador" (v. 34) e um "traductor de aluguer" (v. 51) que "a soldo d'um frade, ao mundo embutes/ Rasteiras copias de originaes soberbos!" (v. 52-53). Bocage, por sua vez, responde seu contemptor com uma sátira intitulada Pena de Talião; e, chamando-o "sanguisuga de putridos auctores" (v. 89) e "contradictorio, túmido versista" (v. 281), o desafia (v. 253-264):

Ou tu mesmo apresenta, offerece á crise

De gordo original versão mirrhada,

Sulcado o Stacio teu de unhadas minhas,

De muitas, que soffreste, e que aproveitas.

N'elle (oh magoa! oh labéo!) por ti mudados

A pompa na indigencia, o lucto em riso:

Mostra em teus versos as imagens suas

Tibias, informes, encolhidas, mortas:

[260]

Desdentado leão, leão sem garras,

\footnotetext{
${ }^{7}$ As sátiras de Macedo e de Bocage são citadas a partir da edição presente em Innocêncio da Silva (1899).
} 
Que á longa idade succumbiu rugindo, Mas leão, que de perto inda é terrível, E que no quadro teu vale um cordeiro.

Embora, pelas acusações, se possa distinguir, entre os motivos da contenda, o desempenho no fazer poético - seja na produção de próprio punho, seja naquela via tradução -, é quase impossível não cogitar nas críticas de um e de outro certa verve de desforra, cujos motivos certamente passariam pelas "unhadas" que Bocage diz ter dado no Estácio de Macedo e pelas acusações que Macedo fez a Bocage. Por outro lado, uma vez que ambos parecem partilhar em alguma medida dos mesmos princípios que norteiam suas traduções, como se verá, é provável que a discussão se fundamente mais em questões de performance do que de concepção.

De acordo com Macedo, as traduções de Bocage são "rasteiras copias" (v. 53); mas não o são, pode-se dizê-lo, simplesmente por serem traduções: a presença de um adjetivo para qualificar negativamente a tradução faz pressupor que existam traduções que não sejam rasteiras, ou mesmo que sejam o seu contrário, pois, se estas não existissem, o termo seria desnecessário. De maneira análoga, quando o chama "fanfarrão glosador” (v. 34), não é porque Bocage faz glosas em seus trabalhos, mas porque ele chama de inspiração divina a amplificação de "cediços motes": "Fanfarrão glosador, chamas divina/ Celeste inspiração, celeste fogo,/ gritando amplificar cediços motes?” (v. 34-36). A invectiva aqui se dá, pois, contra o objeto, e não contra a prática da glosa. Assim também pode ser entendida aquela presente nos versos 55-57 (“Teus improvisos quaes? Glosar tres mottes/ Com logares communs de facho e setas,/ Velhos arreios do menino Idalio?”), em que não é por glosar que Elmiro ataca Elmano, mas por fazê-lo usando "logares communs". Em “traductor de aluguer" (v. 51), é pela venalidade que se acusa, e por fazer "Rasteiras copias de originaes soberbos" (v. 53); e o mesmo vale para "insulso traductor" (v. 90). Para Macedo, a prática da tradução é atividade menor do que aquela de ser poeta ${ }^{8}$ - "Glosar, e traduzir, isto é

\footnotetext{
${ }^{8}$ Como o demonstra João Angelo Oliva Neto em sua introdução às Metamorfoses de Ovídio na tradução de Bocage (OVÍDIO, 2006).
} 
ser vate?" (v. 58) -, mas, ao menos pelo que é possível levantar a partir de seu ataque a Bocage, o problema não é a tradução em si, nem o modo pelo qual a concebe Elmano, e sim seu desempenho na execução da tarefa: "Vem dos outros a luz; se em ti reflecte/ Apenas manda amortecidos raios" (v. 83-84).

Do mesmo modo caminham os ataques de Bocage: é por ter mudado a pompa em indulgência e o luto em riso que Macedo fez "de gordo original versão mirrhada" (v. 254); e por transformar as imagens de Estácio em outras, "tíbias, informes, encolhidas, mortas" (v. 260), e pintar cordeiro a um leão desdentado, mas que, ainda assim, era um leão (v. 261-264). Aqui também não há qualquer ataque à concepção de tradução de Macedo, aos meios pelos quais ele entende que ela deva ser executada: a questão é de performance, de desempenho ou mesmo de capacidade de levar a cabo aquilo que se entende por traduzir. Sobre isso, no prefácio à tradução do drama Eufemia ou O triunfo da religião, de D’Arnaud, Bocage diz:

Em quanto à versificação, a do Original he harmoniosa, accomodada ao assumpto, branda, ou enérgica, segundo o grao, e qualidade da paixão, que exprime. Estremei-me o que pude em imitálla, e em evitar os Gallicismos, de que abunda grande parte das nossas traducções [...] Cuidei igualmente em conservar na dicção toda a fidelidade possivel, excepto nos lugares onde os gênios das duas linguas discordão muito: então, apoderado do pensamento do Author, tratei de o representar a meu modo, conformando-me nisto ao sabido, mas pouco executado preceito de Horacio: nec uerbum uerbo curabis reddere fidus/ interpres. (BOCAGE, 1793, p. 4).

A ideia do bem traduzir para Bocage relaciona-se, então, tanto à observância quanto ao tratamento dispensado a duas características do texto de D'Arnaud: a harmonia entre a versificação e o assunto tratado, que ele se esforçou por imitar, e a dicção que ele buscou conservar sempre que possível, mas que não se furtou a representar a seu modo quando 
julgou muito discordantes os gênios das duas línguas. Se, no prefácio, essa postura está a serviço do texto de D'Arnaud, em sua já citada Pena de Talião Bocage a traz como um princípio da prática tradutória (v. 200-205):

Verter com melodia, ardor, pureza,

O metro peregrino em luso metro,

Dos idiotismos applanando o estorvo,

D'um, d'outro idioma discernindo os genios,

O caracter do texto expôr na glosa,

Proprio tornando, e natural o alheio.

Esse modo de traduzir, aplanando o estorvo dos idiotismos, expondo pela glosa o caráter do texto e tornando o alheio próprio e, principalmente, natural, é o que caracteriza todo um modo de tradução que ganha, com Bocage, sua máxima expressão: o Elmanismo é vertente tradutória em que a eurritmia e a legibilidade da tradução são os principais objetivos. ${ }^{9}$

É também em um prefácio que Macedo revela sua postura ante a prática tradutória. Na Prefação à sua tradução de Horácio (1806), o autor dedica especial destaque aos processos de naturalização da expressão ovidiana com vistas à legibilidade e à manutenção de seu tom, considerando, tal como Bocage, a primazia do pensamento do autor sobre a dicção da língua de partida:

Tem com tudo esta Traducção duas difficuldades da parte do mesmo Original para que sáia literal, e exactamente fiel: a primeira he, a exotica Sintaxe de que o Poeta usa: tem formulas particulares, e Helenismos, que se apartão muito do mechanismo ordinario da Lingoa Latina; porém, como eu não intento dar ao meu nome a dezinencia em $u s$, degolese quem quizer por hum Archaismo, ou por um Solecismo, porque eu estou persuadido, que as Traducções, devem-se dar por pezo, e não por medida, e quando he impossível achar o identico, basta que se encontre o equivalente: e quando absolutamente se

${ }^{9}$ Sobre isso, cf. Vieira, 2015. 
não póde verter a fraze latina na fraze correspondente Portugueza, he licito dar em outra fraze diversa o mesmo sentido do Auctor. (MACEDO, 1806, p. xx).

A literalidade na tradução apregoada por Macedo é, pois, característica marcante em sua concepção. Porém, embora costumeiramente se atribua à tradução literal a ideia de uma tradução colada a tal ponto no original que até mesmo suas características sintáticas seriam emuladas na língua da tradução, ainda que nela se forçassem construções estranhas, a literalidade macedina está mais perto da legibilidade buscada por Bocage: "[aquele] que na Traducção em verso de Poetas Latinos, não despreza minucias Gramaticaes, não vence a difficuldade, e desta maneira venço eu, ou ao menos afronto a primeira" (MACEDO, 1806, p. xx-xxi). Se Bocage se lamentava pelos galicismos que, via tradução, nos “[...] enxovalhão o fertil, e majestoso Idioma, só indigente, e inculto na opinião das Pessoas, que o estudarão mal" (BOCAGE, 1793, p. 4), Macedo manda que se degolem aqueles que quiserem um arcaísmo ou solecismo, e vê sua língua pátria "[...] quasi tão rica, e tão harmoniosa como a Latina" (MACEDO, 1806, p. xix). Concebendo a língua portuguesa como uma língua capaz de expressar aquilo que os poetas expressaram em outras línguas e, no caso em que a língua só não baste, concebendo a si próprios como tradutores capazes de botar em frase diversa o sentido do autor, Bocage e Macedo, adversários declarados, partilham de concepções quase as mesmas quando pensam a tradução.

E é justamente essa postura ante a tradução que parece ter legado o Horácio de Macedo a um segundo plano entre os seus compatriotas já à época do seu lançamento. Publicada em 1806, as odes e os epodos traduzidos por Elmiro não impediram o lançamento das odes horacianas traduzidas por Antônio Ribeiros dos Santos, o Elpino Duriense, já em 1807. Estas, segundo Innocêncio da Silva, eram tão superiores literária e artisticamente às de Macedo que fizeram encalhar nos depósitos da Imprensa Nacional a maior parte de seus exemplares, embora Elmiro proclamasse falsamente que a edição se esgotara rapidamente (SILVA, 1899, p. 48). José Maria da Costa e Silva, o Elpino Nonacriense, aponta como principais aspectos negativos da empreitada de Macedo a 
verbosidade, o prosaísmo e o alargamento, sendo este responsável por considerável acréscimo de versos em comparação com o original, bem como por um enfraquecimento de sua força expressiva; o deslocamento de ideias e imagens presentes no texto latino também é atacado por Costa e Silva, para quem, agindo assim, Agostinho não fez mais que "[...] pôr em versos as traducções francezas em prosa" (COSTA E SILVA apud SILVA, 1899, p. 49, nota 1). Vale a pena, ainda, a leitura da conclusão da crítica de Costa e Silva:

Mas o traductor, que nunca fez estudo serio da lingua materna é muito sujeito a cahir em barbarismos, solecismos, phrases menos cultas, e plebêas. E com uma obra tão defeituosa é que este homem queria restituir o antigo esplendor ao astro da Poesia Portugueza, que elle representava, senão ecclipsado, ao menos quasi escurecido de todo! (COSTA E SILVA apud SILVA, 1899, p. 52, nota de rodapé).

Também são essas, pois, as características que mais chamam a atenção no trecho de sua tradução da Tebaida presente no Códice CXXII da Biblioteca de Évora. Os 79 versos constantes nos fólios 6 e 7 traduzem os 41 primeiros versos do texto de Estácio - trecho que Macedo chama de "dedicatória" do poema. De início, então, já se pode perceber que a passagem quase dobra de tamanho, para o que colaboram principalmente as glosas feitas pelo tradutor, as paráfrases e a sua verbosidade, tal como apontara Costa e Silva com relação à tradução de Horácio. Consideremse, por exemplo, os seguintes versos do texto latino (Theb. 1.7-9): longa retro series, trepidum si Martis opertil agricolam infandis condentem proelia sulcis/ expediam ("longa sucessão em retrocesso se, inquieto com Marte oculto,/ o agricultor que enterra batalhas em sulcos infandos/ eu expuser”). ${ }^{10}$ No contexto, logo após indagar as Musas pelo início de seu canto, o narrador passa à enumeração de alguns episódios relacionados à

${ }^{10}$ Os trechos em latim do poema de Estácio são citados conforme a edição de D. R. Shackleton Bailey (ESTÁCIO, 2003). Todas as traduções, com exceção das indicadas nas Referências Bibliográficas, são de minha autoria. 
história de Tebas. Nesses versos, refere-se ao incidente em que Cadmo, tendo chegado ao local da Beócia onde deveria fundar a cidadela de Tebas, após seus companheiros terem sido mortos por uma serpente filha de Marte que guardava uma fonte de água próxima dali, foi orientado por Minerva, tendo matado o monstro mavórcio, a semear-lhe os dentes sobre o solo beócio. Da sementeira feita pelo herói nasceram os guerreiros conhecidos por Espartos (do grego spartol - "semeados"), os quais batalharam um contra o outro até que restaram vivos apenas cinco deles. Estes, por sua vez, acabaram por ajudar Cadmo na construção da cidadela, tornando-se os ascendentes maiores das primeiras famílias tebanas.

O passo se inicia com o sintagma longa retro series, pelo qual Estácio diz serem antigas e genealogicamente distantes da família de Édipo as histórias que serão arroladas já na sequência - das quais a primeira é a de Cadmo. De formulação bastante sintética - Estácio usa apenas sete sílabas para compô-lo, ou dois pés datílicos e meio -, o sintagma é desdobrado por Macedo em dois decassílabos quase inteiros: "Mas d'apartada e de remota Fonte/ Correrião meus versos" (v. 11-12). Assim, o tradutor introduz uma imagem que não consta na síntese estaciana, pois a fonte da qual correriam os versos é sua criação. Por outro lado, suprime a ideia de sucessão (series), importantíssima em todo o épico, seja porque a guerra entre os irmãos Polinices e Etéocles se dá por desentendimentos quanto à hierarquia do trono, seja porque é a sucessão de crimes em Tebas que será castigada por Júpiter por meio da batalha entre os edipônidas. ${ }^{11}$

Deve-se perceber, ainda, que os adjetivos escolhidos para traduzir o longa e o retro latinos criam, no que diz respeito à "fonte", uma relação diferente daquela entre os termos latinos e o substantivo series: se, em latim, o advérbio retro indica mais o movimento em cuja direção ocorre o olhar sobre a sucessão - pois ela será considerada como uma sucessão, mas vista a partir do seu ponto culminante, e não do inicial -, a "fonte" macedina é apenas distante no espaço e no tempo, algo como uma fonte antiga e longínqua. Dessa forma, perde-se o movimento do olhar do narrador que, estabelecendo a casa de Édipo como seu assunto e,

${ }^{11}$ O que o próprio rei dos deuses declara ainda durante o Canto Primeiro (Theb. 1.197ss.). 
consequentemente, vendo a partir daí os acontecimentos a ela anteriores, marca tanto o presente como o passado da narrativa. Localizando temporalmente a casa de Édipo na história da cidade, Estácio, embora não se detenha no criminoso passado tebano, não diminui sua importância, forjando uma brecha para ao menos passá-lo em revista.

E o narrador, então, relata o episódio em pouco mais de um hexâmetro e meio: [...] trepidum si Martis operti/ agricolam infandis condentem proelia sulcis/ expediam, que Macedo traduz em quatro decassílabos, parafraseando e glosando em uma tentativa de aclarar detalhes do episódio narrado (v. 13-16): "Expor, cantando, a fratercida Messe/ Que vio prestes brotar da infame terra/ Expavorido Lavrador, que os dentes/ Do Dragão de Mavorte semeára". Elmiro desdobra expediam em uma construção, hiperbólica ("expor, cantando”), já que "expor”, para traduzir o verbo latino, dispensa explicitações de modo - além da quase identidade sonora entre ambos os termos (expediam - expor). $\mathrm{O}$ enigmático trepidum [...] Martis operti, construção que indica o medo que Cadmo sentia de Marte, oculto no monstro que ele matara, é simplificado por "espavorido", que não deixa clara a origem do medo. Note-se também que, no texto de partida, é justamente essa imagem que indica, ainda que obliquamente, a paternidade do monstro. Sendo assim, Macedo, para dar conta dessa informação - é quase truísmo destacar Marte como uma figura importante no poema como um todo -, teve de parafraseá-la em um prosaico "[...] que os dentes/ do Dragão de Mavorte semeára". O seu "fratercida Messe", apesar de glosa, foi uma boa escolha para o proelia latino, uma vez que "messe" se refere àquilo que se colhe, e que o fratricídio não só é o crime que os Espartos cometem, ${ }^{12}$ mas também esclarece o vínculo entre o episódio e o tema central do poema: a guerra entre os irmãos, filhos de Édipo e Jocasta. "Que vio prestes brotar" é paráfrase que expande, com o "semeára", o evento causado e presenciado por Cadmo.

Ao fim, os pouco mais de dois versos de Estácio estendem-se por seis versos, ao todo, na tradução de Macedo (v. 11-16), um ótimo exemplo do alargamento que Costa e Silva criticou nas traduções de

\footnotetext{
${ }^{12}$ Eram, pois, filhos da terra e dos dentes da serpente de Marte.
} 
Horácio. A inclusão de trechos e informações via glosa certamente visa ao esclarecimento de episódios mitológicos, sempre referidos de maneira bastante ligeira e concisa por Estácio; sobre isso, chamam a atenção duas inclusões e uma omissão feitas pelo tradutor. O verso 11, em que o narrador estaciano cita como um caminho possível para o seu canto os episódios que teriam levado Baco a irar-se contra Tebas - unde graues irae cognata in moenia Baccho ("Donde as graves iras de Baco contra os muros cognatos") -, não foi traduzido por Macedo, que sequer menciona o nome do deus na tradução. ${ }^{13}$ No verso seguinte, porém, o tradutor desdobra o outro possível assunto indicado pelo narrador quod saeuae Iunonis opus ("qual a obra da seva Juno") -, fazendo com que se esclareça o episódio sutilmente referido no original e que se assinale, ligeiramente, tal como Estácio o faria, uma das consequências do nascimento de Baco - a saber, a morte de Sêmele, sua mãe, que, incitada por Vênus, fez com que Júpiter a ela se mostrasse em toda a sua divindade, o que acabou a fulminando imediatamente: “Ou de Juno o furor, ou da enganada/ Incrédula Semélle o Raio acezo" (v. 21-22). Os versos 23 e 24 da tradução também trazem informação que visa ao esclarecimento, pois a subordinada que descreve o crime de Atamante contra seu filho não existe no original: "As iras d'Atamante, que a Learco/ Da vida despojou co-a seta aguda" traduz cui sumpserit arcus/ infelix Athamas ("Por quem tomou o arco/ o infeliz Atamante"). Por fim, do ponto de vista do esclarecimento histórico, destacam-se os versos 33 e 34 da tradução, "[...] vossos triunfos grangeados/ Nos vastos climas do gelado Arcturo", que traduzem o conciso Arctoos [...] triumphos (1.18 - "os Arcturos triunfos") estaciano.

Também a verbosidade está presente na tradução, especialmente no que diz respeito à inclusão de adjetivos inexistentes no original, atribuindo uma característica ao texto que não é utilizada por Estácio de uma tal forma: "origem triste" (v. 7) para traduzir os primordia (1.4 "primórdios") da geração tebana; "triste Cadmo" (v. 9), "infeliz Cadmo"

\footnotetext{
${ }^{13}$ Esta afirmação deve ser, contudo, amenizada, uma vez que não foi descoberta a edição do texto latino utilizada por Agostinho, da qual o verso 1.11 aqui citado poderia, dentre outras possibilidades, estar ausente.
} 
(v. 28), "mar profundo" (v. 10), "maga força" (v. 18), "justas leis" (v. 36), "ínclito Mancebo" (v. 41) e "doce Cithera" (v. 62); "bravas ondas" (v. 26), para um simples ingens, "tenro filho" (v. 27) para Palaemone, dentre outros. Somados, esses modi operandi do traduzir de Macedo acabam tornando prosaicos alguns trechos bem mais poéticos do texto original, os quais exploram as possibilidades expressivas do hexâmetro latino levando em conta cesuras e posições de palavras. No verso 19 do texto de partida, por exemplo, o narrador se refere de modo sintético tanto às duas vitórias da Primeira Legião Minerva contra os Catos na região do Rio Reno - a primeira em 82, sob o comando direto de Domiciano, e a segunda em 89 - como também às duas incursões contra os Dácios na região do Rio Danúbio - a primeira delas em 85-86, e a segunda em 8788: bisque iugo Rhenum, bis adactum legibus Histrum ("Duas vezes pelo jugo o Reno, duas vezes o Istro dirigido pelas leis"). Macedo distende as informações em dois decassílabos, desconsiderando a distribuição dos dois conjuntos de duas vitórias em dois hemistíquios separados por

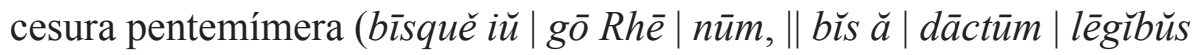
| Hisstrūm): "E ja por duas vezes submetidos/ Ao jugo, e justas leis, o Reno, e o Istro" (v. 35-36).

É igualmente significativo o deslocamento de imagens operado por Elmiro já no início do canto, outro aspecto destacado por Costa e Silva em sua crítica. É fato sabido que a primeira palavra de um poema constitui uma posição bastante importante em que os poetas costumam colocar uma palavra que sintetize, de alguma forma, o assunto de seu canto. Em Homero, por exemplo, mas também em Virgílio e Lucano, para citarmos apenas os mais conhecidos, percebemos tal costume realizado de maneira exemplar: a dupla mênin e ándra da Ilíada e da Odisseia homéricas, respectivamente, condensam o principal de cada um dos carmes: a ira de Aquiles e Odisseu, o homem. Em Virgílio, as duas primeiras palavras, arma uirumque ("as armas e o homem"), condensam os dois assuntos principais de sua Eneida; em Lucano, são as bella ("as guerras") a matéria do canto. Em Estácio, não é diferente: o objeto do seu estro são as fraternas acies, as "fraternas hostes". O sintagma estaciano, porém, é referência ao cognastaque acies ("e as hostes 
cognatas") que abre o quarto verso da Farsália (Luc. 1.4), colocando em destaque, assim, não só a relação entre a Tebaida e o épico de Lucano, mas também a imitatio, um processo composicional utilizado pelo autor em toda a sua obra, bastante comum em toda a literatura romana, e que é reconhecido pela crítica como fundamental tanto do texto de Estácio como da literatura imperial romana. ${ }^{14}$ Macedo, porém, inverte a ordem das imagens na proposição, antepondo, a fraternas acies, a referência à inspiração do canto pelas musas do monte Píero (v. 1-5). Com isso, o destaque e a importância dada pelo poeta ao sintagma acabam por se enfraquecer, embora se mantenham, em boa tradução, a expressão latina e a sua posição dentro do verso:

Piéria chama, que ateada ferve

Dentro do peito a decantar me obriga

As armas fraternais: da iníqua Thebas

O trono alternativo, e disputado

Com profano rancor.

Por fim, e antes que se apresente a edição do manuscrito, é imprescindível que se reconheça o esforço de José Agostinho de Macedo não somente em traduzir o poema de Estácio, mas em trazêlo à tona durante um período fundamental para o desenvolvimento das letras portuguesas no qual a tradução dos clássicos da antiguidade greco-latina desempenhou papel importantíssimo. Com seu espírito hiperbólico, Macedo não só louvou Estácio, que, antes de qualquer coisa, é nome importante na história da literatura romana, como também e principalmente pôs na história da recepção dos clássicos da antiguidade greco-latina em língua portuguesa um poeta até hoje inédito entre nós, unindo Estácio, em português, a Homero, Virgílio e Lucano, nomes aos quais certamente o próprio Estácio desejou unir-se durante sua vida. Independentemente dos juízos que se atribuam à sua tradução, portanto, seus valores históricos e culturais, ao menos, são inegáveis, e reforçam ainda mais o pertencimento de Macedo à galeria de tradutores portugueses dos sécs. XVIII e XIX.

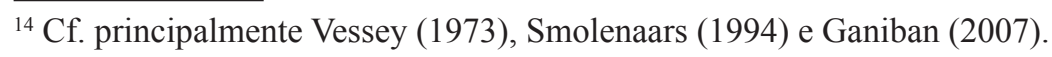


[Fl.1]

\section{Thebaida \\ Livro $1^{\circ}$}

Piéria chama, que ateada ferve

Dentro do peito a decantar me obriga

As armas fraternais: da iníqua Thebas

$\mathrm{O}$ trono alternativo, e disputado

Com profano rancor. Musas por onde

Me mandais caminhar? Direi primeiro

A origem triste da perversa gente,

$\mathrm{O}$ furto de sidonia, a ley sevéra

Do cruel Agenor? Do triste Cadmo

A vida errante pelo mar profundo?

Mas d'apartada e de remota fonte

Correrião meus versos, se quisera

Expor, cantando, a fratercida Messe

Que vio prestes brotar da infame terra

Expavorido Lavrador, que os dentes

Do Dragão de Mavorte semeára.

Ou se intentasse celebrar em versos

A maga força d'Anfionias Liras

Q'as pedras atrahio dos altos montes

Quando de Thebas levantava os muros.

Ou de Juno o furor, ou da enganada incrédula Semélle o Raio acezo.

As iras d'Atamante, que a Learco

Da vida despojou co-a seta aguda

E como sem temor se precipite

[F1.2]

Ino, do mar de Jônia às bravas ondas

Levando o tenro filho entre seos braços.

Mas fiquem no silencio infeliz Cadmo

Suas acçoens, e lagrimas. D'Edîpo

A confuza família de meo canto,

Será princípio, será termo agora.

Enquanto inda não posso, Águias de Roma 
Cantar vossos triunfos grangeados

Nos vastos climas do gelado Arcturo

E ja por duas vezes submetidos

Ao jugo, e justas leis, o Reno, e o Istro

E das montanhas orridas expulsos

Os conjurados, e ferozes Gétas

E por ti defendido o Capitolio

$\mathrm{Na}$ tenra Idade, nos primeiros annos

Oh ínclito Mancebo, oh Brasão novo

Da Lacia terra, da Romana Fama

Que proceguindo as paternais Emprezas

Obrigas já do Mundo a soberana

A desejar o teo imperio eterno

Inda que as altas lúcidas estrellas

Apertando-se mais, lá te preparem

Hum lugar entre si, inda que o Pollo

Onde brilhão as Pleidas te chame

E te assinale hum trono onde não chega

$\mathrm{O}$ vento, a fria neve, o raio ardente

E o domador de ignipedes cavallos

Deseje com seos raios fulgurantes

Circundar teos cabellos ondeados

inda que queira Jupiter supremo

Cederte igual porção do Eterio Assento

[F1.3]

Co-o governo dos homens te contenta

E justas leis ditando ao mar, e a Terra

Deixa que impére Jupiter nos Astros.

Inda tempo hade vir emq.' inflamado

De mais alto furor teos feitos cante:

Agora a doce Cithera encordo'o

E deixa que te exponha as duras armas

E Ceptro fatal sempre aos dois Tiranos.

A Fúria inda ca-a morte não findada,

A sedição das chamas crepitantes

$\mathrm{Na}$ funeral e devidida Pira

Os corpos de Monarchas insepultos

Pasto d'Abutres, e d'alpestres Feras 
Tantas cidades ermas, assoladas

Q'alternativa morte despovóa

Quando as agoas de Dirce se mudarão

Na rubra cor de sangue, enquanto Thetis

Vio assombrada o fluctuante Ismeno

Não pellas margens aridas correndo

Mas entrar proceloso, e turvo e rouco

C'hum motão decadáveres nos mares.

Qual de tantos Heroes, primeiro oh Clio

Me mandas celebrar.....

JAM.

\section{Agradecimentos}

Este trabalho tomou forma durante o levantamento bibliográfico feito para a minha tese de doutorado, intitulada $A$ Tebaida, de Públio Papínio Estácio: introdução, tradução e comentários (cantos I-V), desenvolvida no Programa de Pós-Graduação em Estudos Literários da Faculdade de Ciências e Letras da UNESP de Araraquara - SP com o fomento da CAPES/DS e defendida nos fins de maio de 2018. Assim sendo, agradeço às leituras e sugestões feitas por meu orientador, Prof. Dr. Brunno Vinicius Gonçalves Vieira, bem como pelo suporte oferecido durante a edição do manuscrito de Macedo. Por este motivo, também agradeço o auxílio do Prof. Dr. Alessandro Rolim de Moura (UFPR).

\section{Referências}

BOCAGE. Ao leitor. In: D’ARTAUD, F. T. M. de B. Eufemia, ou o triunfo da religião. Tradução de M. M. B. du Bocage. Lisboa: Off. Simão Thadeo Ferreira, 1793. p. 3-4.

COUTO, A. M. do. Exame critico do Motim Litterario de José Agostinho de Macedo. Lisboa: Impressão Régia, 1811.

COUTO, A. M. do. Breve analyse do novo poema que se intitula Oriente: por hum amigo do publico. Lisboa: Nova impressão da viúva Neves e Filhos, 1815a. 
COUTO, A. M. do. Manifesto crítico, analítico e apologético: em que se defende o insigne vate Luiz de Camões, da mordacidade do discurso preliminar, que precede ao poema Oriente, e se demonstrão os infinitos erros do mesmo poema. Lisboa: Impressão de J. F. M. de Campos, 1815 b.

COUTO, A. M. do. Biographia historica, e literaria, sobre Joze Agostinho de Macedo, e critica avaliação de suas muitas, e diversas composições. In: MACEDO, J. A. de. Motim literário em forma de solilóquios. Edição de Antônio Maria do Couto. Lisboa: Tipografia de Antônio José da Rocha, 1841. t. 1, p. 3-94.

D'ARTAUD, F. T. M. de B. Eufemia, ou o triunfo da religião. Tradução de M. M. B. du Bocage. Lisboa: Off. Simão Thadeo Ferreira, 1793.

GANIBAN, R. Statius and Virgil: the Thebaid and the Reinterpretation of Aeneid. Cambridge: Cambridge University Press, 2007.

HORÁCIO. Obras de Horácio, traduzidas em verso portuguez por José Agostinho de Macedo. Lisboa: Impressão Régia, 1806. t. 1.

HORÁCIO. A lyrica de Q. H. Flacco, poeta romano, trasladada literalmente em verso portuguez por Elpino Duriense. Lisboa: Impressão Régia, 1807.

MACEDO, J. A. de. A analyse analysada: resposta a Couto, por José Agostinho de Macedo. Lisboa: Impressão Régia, 1815.

MACEDO, J. A. de. Gama: poema narrativo. Lisboa: Impressão Régia, 1811.

MACEDO, J. A. de. Motim literário em forma de solilóquios. Edição de Antônio Maria do Couto. Lisboa: Tipografia de Antônio José da Rocha, 1841a.t. 2.

MACEDO, J. A. de. Motim literário em forma de solilóquios. Edição de Antônio Maria do Couto. Lisboa: Tipografia de Antônio José da Rocha, 1841b. t. 3.

MACEDO, J. A. de. O Oriente: poesia de José Agostinho de Macedo. Lisboa: Imprensa Régia, 1814. 2 v.

MACEDO, J. A. de. Obras inéditas de José Agostinho de Macedo: cartas e opúsculos. Prefácio de Theophilo Braga. Lisboa: Tipografia da Academia Real das Ciências, 1900. 
MACEDO, J. A. de. Prefação. In: HORÁCIO. Obras de Horácio, traduzidas em verso portuguez por José Agostinho de Macedo. Lisboa: Impressão Régia, 1806. t. 1, p. v-xxxvi.

MENÉNDEZ Y PELAYO, M. Horácio en España. 2 ed. Madrid: Imprenta de A. Pérez Dubrull, 1885. t. I.

OVÍDIO. Metamorfoses. Tradução de M. M. B. du Bocage. São Paulo: Hedra, 2006.

REQUIÃO, A. Um livro quinhentista. Gazeta de Notícias, Bahia, 9 jun. 1913. n. 224, p. 2. Disponível em: <http://memoria.bn.br/ docreader/721026/945>. Acesso em: 30 abr. 2018.

SILVA, I. F. da. Memórias para a vida intima de José Agostinho de Macedo. Edição de Theophilo Braga. Lisboa: Tipografia da Academia Real das Ciências, 1899.

SMOLENAARS, J. J. L. Statius Thebaid VII: a commentary. Leiden; New York; Köln: Brill, 1994.

STATIUS, P. P. Thebaid: books 1-7. Edited and translated by D. R. Shackleton Bailey. Cambridge: Harvard University Press, 2003. v. 2.

VESSEY, D. Statius and the Thebaid. Cambridge: Cambridge University Press, 1973.

VIEIRA, B. V. G. Bocage e Filinto: duas maneiras de traduzir os Clássicos. Boletim de Estudos Clássicos, Coimbra, v. 60, p. 167-179, 2015.

Recebido em: 30 de abril de 2018. Aprovado em: 21 de maio de 2018. 